06

\title{
Локализация света в полимере на основе эпоксиакрилового композита, модифицированном нанокластерами ZnO
}

\author{
() В.И. Иванов-Омский ${ }^{1}$, И.Е. Истомин ${ }^{1,9}$, О.Э. Бабкин ${ }^{2}$, Л.А. Бабкина ${ }^{2}$, Т.Н. Василевская ${ }^{1}$, К.В. Изотова ${ }^{2}$, \\ M. Singh ${ }^{3}$, С.Г. Ястребов ${ }^{1}$ \\ ${ }^{1}$ Физико-технический институт им. А.Ф. Иофрфе РАН, Санкт-Петербург, Россия \\ ${ }^{2}$ Санкт-Петербургский государственный институт кино и телевидения, Санкт-Петербург, Россия \\ ${ }^{3}$ Western University, London, Ontario, Canada \\ `E-mail: kesha22ist@gmail.com
}

Поступило в Редакцию 23 апреля 2021г.

В окончательной редакции 28 мая 2021 r.

Принято к публикации 29 мая 2021 г.

\begin{abstract}
На примере прохождения света через слой полимера на основе эпоксиакрилового композита, модифицированного нанокластерами $\mathrm{ZnO}$, сформулировано условие резонанса, обеспечивающего наблюдение голубой окраски при хаотическом расположении рассеивателей. Проведенный анализ использован для объяснения экспериментальных данных.
\end{abstract}

Ключевые слова: когерентное рассеяние, люминесценция, метаматериалы.

DOI: 10.21883/PJTF.2021.17.51386.18841

В последнее время возрос интерес к так называемым метаматериалам, т.е. к любым материалам, спроектированным так, чтобы иметь некое свойство или набор свойств, которые не встречаются в материалах природного происхождения [1].

С точки зрения простоты технологической реализации интересны в первую очередь материалы, при синтезе которых имеет место самоорганизация различных наноразмерных фаз. В качестве примера можно привести фотоотверждаемые полимеры, в которые достаточно просто ввести нанокристаллические добавки, например нанокластеры $\mathrm{ZnO}[2,3]$. При этом в неупорядоченных средах может наблюдаться, как это предсказано в работе [4], явление когерентного рассеяния света. Однако в литературе ощущается нехватка экспериментальных данных, подтверждающих существование этого явления. Поэтому интересным представляется исследование оптических свойств сред, содержащих стохастически распределенные рассеиватели.

В настоящей работе сообщается о наблюдении голубой окраски в слоях эпоксиакрилового композита, модифицированного кристаллами $\mathrm{ZnO}$ нанометрового размера, хаотически распределенными в матрице эпоксиакрилового композита. Это явление напоминает голубую опалесценцию, которая проявляется в образцах, содержащих упорядоченные массивы сфер, допускающие брэгговскую дифракцию в оптическом диапазоне спектра. Технология получения тонких пленок на основе эпоксиакрилового композита, модифицированного нанокластерами $\mathrm{ZnO}$, подробно описана в работах [2,3]. Здесь отметим, что эксперименты проводились с составом на основе эпоксиакрилатного олигомера (57.0 mass\%, молекулярная масса 550, функциональность 2) с добавлением изоборнилакрилата (32 mass\%), метакриловой кислоты (1 mass\%) и смеси фотоинициаторов: 1-гидроксициклогексилфенилкетона $(2.0$ mass \%), а также оксида 2,4,6-триметилбензоилдифенилфосфина (8.0 mass\%). Ингредиенты перемешивались в высокоскоростном растворителе в течение $10 \mathrm{~min}$. Дисперсии нанокристаллов оксида цинка NANOBYK-3841 вводились в состав и диспергировались в диссольвере в течение $20 \mathrm{~min}$. Готовые составы наносились аппликатором на тефлоновые пластины и отверждались в течение $40 \mathrm{~s}$ на установке ОРК-21М с ртутной лампой ДРТ-400. Интенсивность УФ-излучения регистрировалась УФ-фотометром UVPower Puck II (интенсивность УФ-излучения соответствует диапазонам $H A=135 \mathrm{~mW} / \mathrm{cm}^{2}, H B=150 \mathrm{~mW} / \mathrm{cm}^{2}$, $H C=24 \mathrm{~mW} / \mathrm{cm}^{2}, H V=90 \mathrm{~mW} / \mathrm{cm}^{2}$; диапазону $H C$ отвечают длины волн света в интервале $100-280 \mathrm{~nm}$, $H B-280-315 \mathrm{~nm}, H A-315-390 \mathrm{~nm}, H V-$ $390-420 \mathrm{~nm})$. Толщина пленки измерялась микрометром. Толщина пленок, содержащих 4 mass\% нанокристаллов оксида цинка, составляла $1.5-1.4 \mathrm{~mm}$. В работе [2] проведено исследование результатов рентгенофазового анализа пленок. На основе анализа наиболее интенсивной линии рентгеновской дифракции восстановлена функция распределения наночастиц $\mathrm{ZnO}$ по размерам и рассчитан медианный размер этих частиц, который оказался равен 40-50 nm. В нашем случае удалось сфотографировать явление голубого окрашивания слоев полимера, модифицированного оксидом цинка, в условиях дневного света (рассеянный солнечный свет в помещении), снимки делались с помощью фотоаппарата Canon IXUS 185. Спектр люминесценции образцов измерялся спектрофлуориметром Hitachi F4010 в стоксовой области при возбуждении светом с длиной волны $390 \mathrm{~nm}$. Спектры рассеяния образцов измерялись с помощью интегрирующей сферы с использованием 

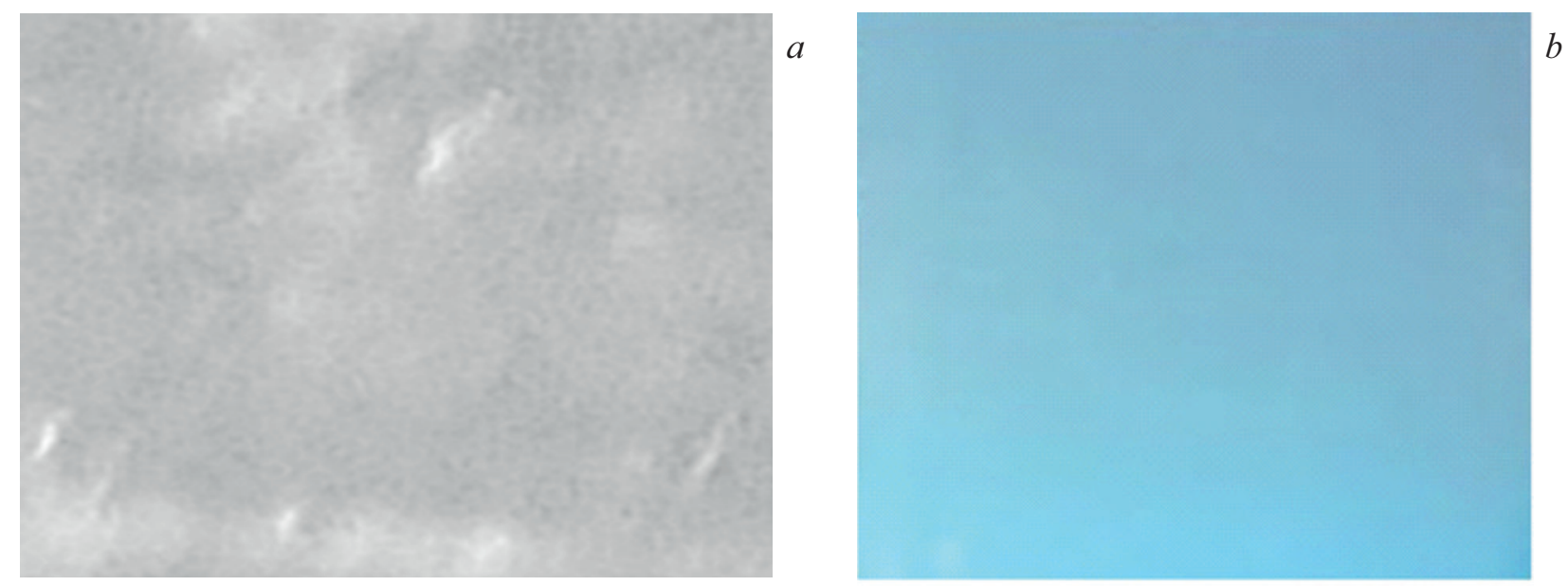

Рис. 1. Общий вид образцов, содержащих $0(a)$ и 4 mass\% $\mathrm{ZnO}(b)$. Размер нижней стороны образца $2 \mathrm{~cm}$.

спектрофотометра Shimadzu UV-3600 для диапазона длин волн 150-650 nm. Прибор оснащен интегрирующей сферой для измерения спектров интегрального рассеяния и экстинкции.

В результате осмотра образцов установлено, что голубая окраска наблюдалась в слоях эпоксиакрилового композита, модифицированного нанокластерами $\mathrm{ZnO}$. С целью фиксации окраски использовалось фотографирование. На рис. 1, а приведена фотография образца, содержащего 0 mass\% $\mathrm{ZnO}$. Результат для 4 mass\% $\mathrm{ZnO}$ показан на рис. $1, b$. Голубая окраска наблюдается для образца, содержащего 4 mass\%, и не наблюдается для немодифицированного образца. Исходные интегральные спектры и их разность для этих двух образцов представлены на рис. 2, $a$ и $b$ соответственно.

Из рис. 2, $b$ видно, что в общий вклад в разность спектров вносят полоса сложной структуры с максимумом $365 \mathrm{~nm}$, форма которой хорошо описывается суммой трех гауссианов (кривые $1-3$ ), и полоса 4 с максимумом $390 \mathrm{~nm}$. Обе полосы можно приписать вкладу нанокристаллов $\mathrm{ZnO}$. Так, полосу с максимумом $365 \mathrm{~nm}$ можно приписать форме линии оптической экстинкции наноразмерных кристаллов $\mathrm{ZnO}$, внедренных в полимерную матрицу. Качественно это явление можно проинтерпретировать следующим образом. Из литературы [5] известно, что в модели малых факторов заполнения для мнимой части диэлектрической функции композита справедливо выражение

$$
\xi^{\prime \prime} \sim v \frac{\varepsilon_{\mathrm{ZnO}}^{\prime \prime} \varepsilon_{m}^{2}}{\left[\varepsilon_{m}+f_{i}\left(\varepsilon_{\mathrm{ZnO}}^{\prime}-\varepsilon_{m}\right)\right]^{2}+\left(f_{i} \varepsilon_{\mathrm{ZnO}}^{\prime \prime}\right)^{2}} .
$$

Здесь $\xi^{\prime \prime}$ - диэлектрическая функция смеси наночастиц и полимера, $\varepsilon_{m}$ - диэлектрическая проницаемость полимера, окружающего наночастицу, $v-$ фактор заполнения, $\varepsilon_{\mathrm{ZnO}}^{\prime}, \varepsilon_{\mathrm{ZnO}}^{\prime \prime}-$ действительная и мнимая части диэлектрической функции наночастицы $\mathrm{ZnO}$ соответственно, $f_{i}-$ формфактор вдоль $i$-й оси эллипсоидальной наночастицы (для частиц сферической формы $\left.f_{i}=f=1 / 3\right)$. Очевидно, что при любых значениях $f_{i}$ в случае $\varepsilon_{\mathrm{ZnO}}^{\prime} \approx \varepsilon_{m}$ и случае малого поглощения материала наночастицы $\left(\varepsilon_{\mathrm{ZnO}}^{\prime \prime 2} \approx 0\right) \gamma \sim \varepsilon_{\mathrm{ZnO}}^{\prime \prime} \varepsilon_{m} \quad(\gamma-$ показатель поглощения). В этом случае спектр $\xi^{\prime \prime}$ для наночастицы $\mathrm{ZnO}$ определяется спектром мнимой части диэлектрической функции $\mathrm{ZnO}$. Поэтому для сравнения с рис. 2, $b$ на рис. 2, с приведены спектры оптических функций $\mathrm{ZnO}$. Легко видеть, что положение максимума наиболее заметной полосы на рис. $2, b$ практически совпадает с максимумом мнимой части $\mathrm{ZnO}$, поэтому данную полосу поглощения, принимая во внимание указанное выше, можно связать с поглощением нанокластерами ZnO. Менее интенсивный пик с максимумом при $390 \mathrm{~nm}$ проявляется на разности спектров и может быть связан с когерентным рассеянием света нанокластерами оксида цинка. Природа этого рассеяния рассмотрена далее. Здесь же мы обратимся к спектру люминесценции исследуемого нами материала, который приведен на рис. $2, d$. Для его измерения нами была выбрана длина волны, соответствующая полосе рассеяния с максимумом $390 \mathrm{~nm}$. Это позволит оценить влияние рассеянного на данной частоте света на возбуждение люминесценции полимера. При проведении исследований мы обратили внимание на отсутствие серьезной модификации спектра люминесценции при добавлении в материал наночастиц оксида цинка. Интенсивности люминесценции в максимумах не оценивались, поскольку результаты измерения доступны в относительных единицах. Поэтому на рис. $2, d$ приведена только одна кривая. Из рисунка видно, что выбранный нами полимер люминесцирует в голубой области спектра. Однако, как отмечалось выше, визуально заметная голубая окраска образцов проявляется только в случае модифицированного полимера. Это может указывать на резонансное, или, как его еще называют, когерентное, рассеяние электромагнитного излучения с длиной волны $\sim 390 \mathrm{~nm}$ сетью нанокристаллов оксида цинка. Заметим, что число фотонов в этой коротковолновой спектральной области 

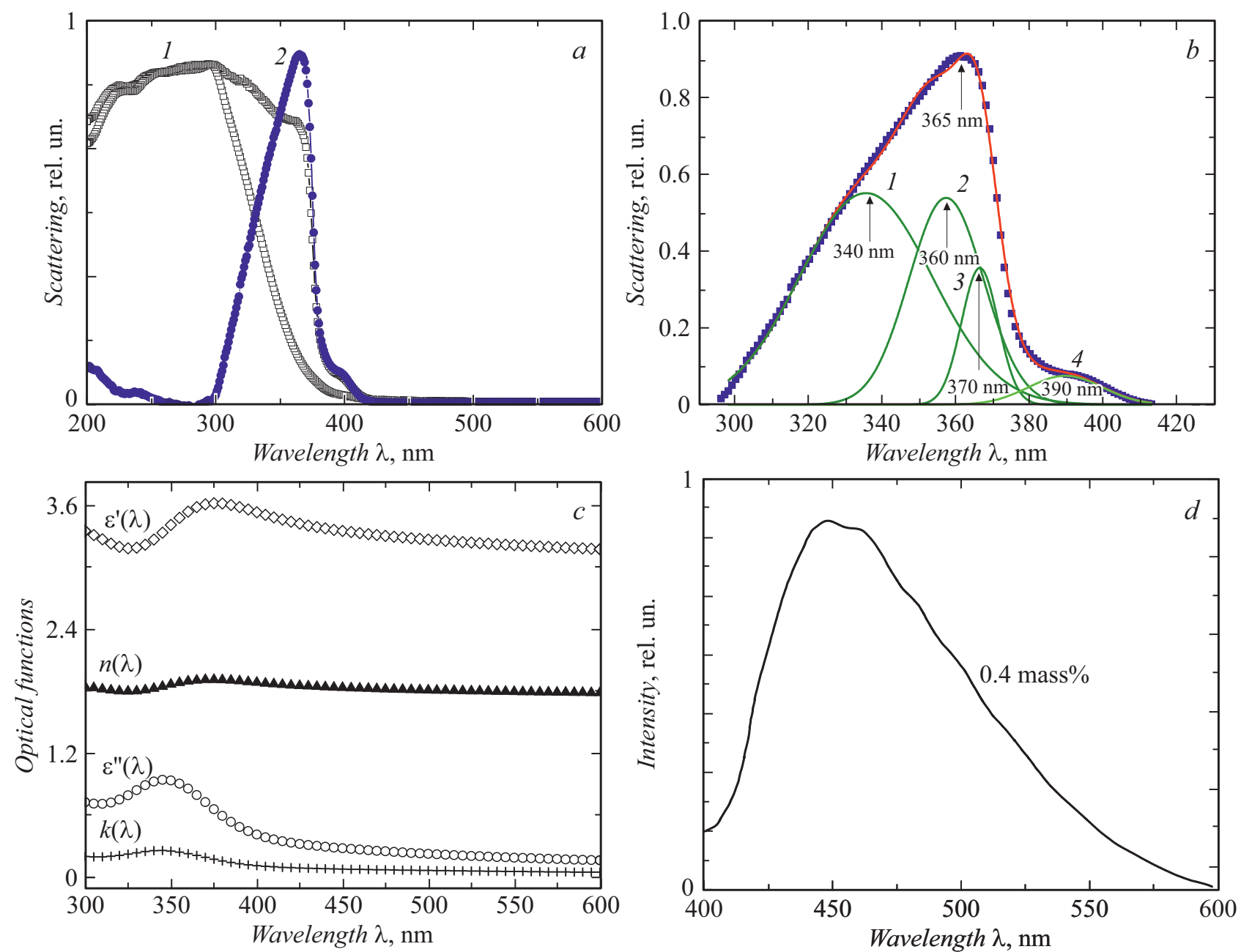

Рис. 2. Спектры рассеяния образцов, содержащих 0 (1) и 4 mass\% $\mathrm{ZnO}(2)(a)$, и их разность $(b)$. На части $b$ представлено разложение на гауссианы, положения всех максимумов отмечены стрелками, около каждой стрелки указано значение длины волны, для которой наблюдается максимум. $c-$ спектр оптических констант для $\mathrm{ZnO} . d-$ спектр люминесценции эпоксиакрилового полимера (различий спектров, измеренных для разных концентраций, выявить не удалось).

при облучении рассеянным солнечным светом невелико, что подтверждает действие механизма когерентного рассеяния света. В этом случае свет попадает в условия, когда благодаря эффекту интерференции реализуется его максимальная интенсивность на определенном участке пути, пролегающем между парами соседних рассеивателей. Заметим также, что интенсивность этого излучения не приводит к изменению структуры спектра люминесценции, оставляя его практически таким же, как и для немодифицированного образца (рис. $2, d$ )

Эффект локализации света в образце может проявляться из-за действия разных причин. Так, нами недавно исследовалась возможность локализации света тонкой пленкой, содержащей нанокластеры [6]. В этом случае локализация света, рассеянного нанокластером, происходит за счет проявления эффекта полного внутреннего отражения рассеянного света на границах пленки. При этом, как показал расчет, выполненный с использованием теории Ми, значительная часть рассеянного света остается в пленке. Свет также может локализоваться в пленке по типу так называемой слабой локализации при реализации траектории движения с самопересечением. Оба эти механизма приводят к захвату света и его своеобразному накоплению в резонаторе. В том случае, если рассеиватели помещены в люминесцирующую матрицу, происходит ее люминесценция. Рассмотрим здесь наиболее вероятный с нашей точки зрения механизм, заключающийся в когерентном рассеянии света при его движении по ломаной траектории. Качественная картина диффузионного движения света через образец, содержащий рассеиватели $\mathrm{ZnO}$, представлена на рис. 3 . Локализация света при движении по ломаной траектории предсказана и подробно рассмотрена в работе [4] (см. также ссылки, приведенные в ней).

На рис. 3 ломаными линиями 1 и 2 показаны пути следования двух фотонов, двигающихся навстречу друг другу из точки $B$ в точку $A$ и из точки $A$ в точку $B$ соответственно. Другими словами, между границами 


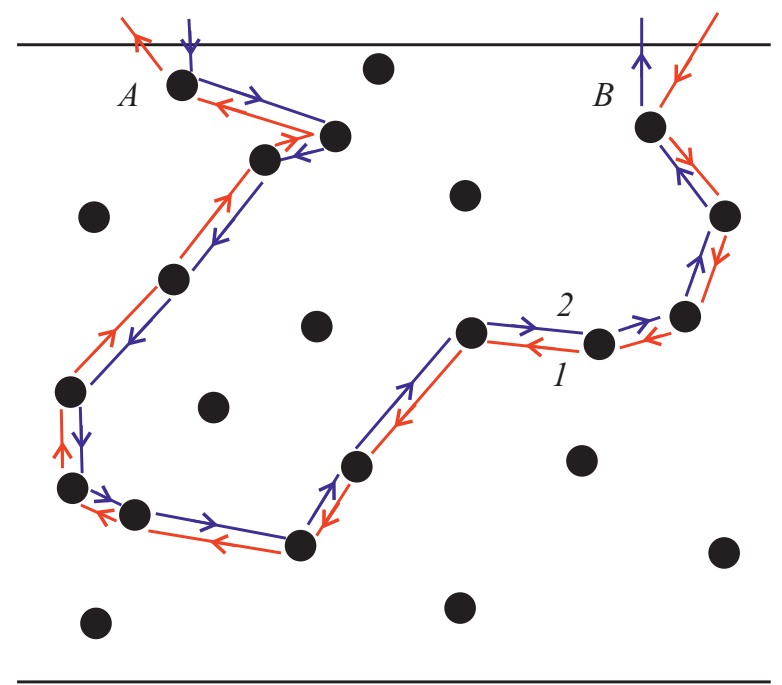

Рис. 3. Пути света при его когерентном рассеянии в образце. Нанокристаллы $\mathrm{ZnO}$ изображены темными кружками. Остальные пояснения в тексте.

зерен нанокристаллов свет движется баллистически, пока не претерпевает рассеяние на нанокристаллах $\mathrm{ZnO}$. В результате рассеяния изменяются фаза и траектория движения фотона. Движение по ломаной линии продолжается до тех пор, пока свет не покидает образец. Если траектории движения, изображенные на рис. 3, совпадают полностью, то возможно наблюдение явления интерференции, выделяющее из спектра отдельные длины волн фотонов. Другими словами, максимальный эффект достигается в случае, когда траектория движения фотонов инвариантна к инверсии знака времени.

Поскольку в явлении интерференции критичным представляется учет фазы электромагнитной волны, для анализа воспользуемся методом оценки величины фазового сдвига при прохождении света между ближайшими частицами. Для простоты считаем расстояния между частицами равными.

Известно, что для усиления волн необходимо, чтобы при движении волны на элементарном участке пути сдвиг фазы был равен $2 \pi \nu$, где $v$ - номер моды $(0,1,2, \ldots)$. Получаются выражения для фазового сдвига и оценки расстояния между краями нанокристаллов оксида цинка $h$

$$
k n_{m} h-\phi=2 \pi \nu
$$

Здесь первое слагаемое характеризует сдвиг фазы при прохождении света между краями соседних рассеивателей сферической формы, $\phi-$ сдвиг фазы, вносимый рассеивателем, в модели мягких шаров [7] он равен

$$
\phi=\frac{4 \pi a n_{m}\left(\frac{n_{\mathrm{ZnO}}}{n_{m}}-1\right)}{\lambda},
$$

где $n_{\mathrm{ZnO}} \approx 1.9 \quad[8]$ и $n_{m} \approx 1.5 \quad[9] \quad$ - показатели преломления пленки и наночастицы соответственно, $a \approx 20 \mathrm{~nm}[2]$ - радиус нанокластера оксида цинка. Легко получить выражение для минимального расстояния между частицами $h=\frac{2 \pi v+\phi}{k n_{m}}$, которое для моды $v=0$ в нашем случае дает значение $h \approx 11 \mathrm{~nm}$ для длины волны $\sim 390 \mathrm{~nm}$.

При рассмотренном механизме рассеяния света может значительно увеличиваться длина его траектории. В этом смысле можно говорить о локализации электромагнитного излучения в образце, т.е. с учетом полученных нами ранее экспериментальных данных для эквидистантной цепочки рассеивателей условия усиления волн, попадающих в область значений длин волн $\sim 390 \mathrm{~nm}$, достигаются с учетом описанной выше модели при расстоянии между краями сферических наночастиц $\mathrm{ZnO}$, равном $\sim 11 \mathrm{~nm}$.

В рамках модели, согласно которой часть нанокластеров $\mathrm{ZnO}$, внедренных в полимерную матрицу, способна когерентно рассеивать свет от естественного источника излучения в области длин волн $\sim 390 \mathrm{~nm}$, расстояние между краями соседних рассеивателей равно $\sim 11 \mathrm{~nm}$. Свет, проходя участки между рассеивателями в полимерной матрице, возбуждает ее, что вызывает ее отклик в виде голубой люминесценции. Эти явления могут объяснить появление голубой окраски опалесцентного типа в эпоксиакриловом полимере, модифицированном наночастицами $\mathrm{ZnO}$.

\section{Благодарности}

Авторы благодарят Ресурсный центр СПбГУ „Оптические и лазерные методы исследования вещества“ за исследование спектров рассеяния образцов на спектральном приборе, оснащенном интегрирующей сферой.

\section{Финансирование работы}

Один из авторов (M. Singh) благодарит Natural Sciences and Engineering Research Council of Canada (NSERC) за предоставление исследовательского гранта.

\section{Конфликт интересов}

Авторы заявляют, что у них нет конфликта интересов.

\section{Список литературы}

[1] G.R. Singh, A. Marwaha, Int. J. Eng. Trends Technol., 19 (6), 305 (2015). DOI: 10.14445/22315381/IJETT-V19P254

[2] О.Э. Бабкин, Л.А. Бабкина, Т.Н. Василевская, М.В. Изотова, П.А. Онущенко, С.В. Козырев, С.Г. Ястребов, ЖПХ, 90 (11), 1540 (2017). [Пер. версия: 10.1134/S1070427217110180].

[3] О.Э. Бабкин, Л.А. Бабкина, Т.Н. Василевская, С.Г. Ястребов, В.Д. Андреева, С.В. Козырев, А.С. Дринберг, М.В. Изотова, О.С. Айкашева, ФТТ, 60 (12), 2470 (2018). DOI: 10.21883/FTT.2018.12.46774.160

[4] S. John, Phys. Today, 44 (5), 32 (1991). DOI: $10.1063 / 1.881300$

[5] Ю.И. Петров, Физика малых частии, (Наука, М., 1982). 
[6] В.И. Иванов-Омский, И.Е. Истомин, М. Singh, С.Г. Ястребов, Письма в ЖТФ, 47 (14), 14 (2021). DOI: $10.21883 /$ PJTF.2021.14.51180.18778

[7] Г. ван де Хюлст, Рассеяние света малыми частицами, пер. с англ. Т.В. Водопьяновой, под ред. В.В. Соболева (ИИЛ, М., 1961).

[8] O. Aguilar, S. Castro, M.P.F. Godoy, M.R. Sousa Dias, Opt. Mater. Express, 9 (9), 3638 (2019).

DOI: 10.1364/OME.9.003638

[9] F. Aloui, L. Lecamp, P. Lebaudy, F. Burel, eXPRESS Polymer Lett., 12 (11), 966 (2018).

DOI: $10.3144 /$ expresspolymlett.2018.83 